OPINION

\title{
Incentivised Sterilisation: Lessons from India and for the Future
}

\section{Jeffrey Wale ${ }^{a}$}

\section{Sam Rowlands ${ }^{b}$}

${ }^{a}$ Department of Humanities \& Law, Faculty of Media and Communication, Weymouth House, Bournemouth University, Fern Barrow, Poole, BH12 5BB, UK

jwale@bournemouth.ac.uk

+44 1202962245

ORCiD: 0000-0002-9210-029X

b Department of Medical Sciences \& Public Health, Faculty of Health \& Social Sciences, Royal London House, Christchurch Road, Bournemouth University, Bournemouth, BH1 3LT, UK

srowlands@bournemouth.ac.uk

ORCiD 0000-0001-5940-9079

Twitter@ @owlands999

\section{Corresponding author:}

Dr Jeffrey Wale 


\section{Author contributions}

SR conceived the idea for the paper. SR did an initial search; JW checked and added to this.

Both authors drafted the manuscript and then edited further drafts. Both authors approved the final version.

\section{Acknowledgement}

None.

Running title: Incentivised sterilisation

Keywords: incentivisation, targets, population, sterilisation, human rights

Word count: 81 words (Abstract); 2,964 words (Main text) 


\title{
Incentivised Sterilisation: Lessons from India and for the Future
}

\begin{abstract}
Family planning programmes in India have historically been target-driven and incentivebased with sterilisation seen as a key component of controlling population growth. This opinion paper uses India as the backcloth to examine the ethics of using incentive policy measures to promote and secure sterilisations within communities. Whilst we acknowledge that these measures have some value in reproductive health care, their use raises specific issues and wider concerns where the outcome is likely to be permanent and life changing for the acceptor.
\end{abstract}




\section{Introduction}

In early February 2020, The Constitution (Amendment) Bill 2020 was introduced into the Rajya Sabha or Upper House of the Parliament of India, seeking amendment to Article 47 of the Constitution of India:

47A. The State shall promote small family norms by offering incentives in taxes, employment, education, etc. to its people who keep their family limited to two children and shall withdraw every concession from and deprive such incentives to those not adhering to small family norm, to keep the growing population under control [1].

Clearly, the proposer's intention is to limit family size using a range of incentives and punitive policy measures, with a view to controlling national population growth [2].

This opinion piece considers the specific use of incentives in connection with national and regional sterilisation programmes, drawing upon a range of contemporary examples and literature focussing on India to develop our central arguments. We do not examine explicit coercion, or incentives offered by non-State actors (including members of an acceptor's family). Nor do we spend any time discussing the key factors for population growth - suffice to say, that some countries have used targeted sterilisation of their citizens when populations are deemed to be too large and/or growing too fast. Although we use the term 'acceptor' to denote the person who has undergone the sterilisation, it should not be construed as meaning that there has been free and informed consent to that procedure. 


\section{Materials and Methods}

Our search strategy was to look for material freely available on the subject of incentivised sterilisation, focusing on examples from the Indian subcontinent. We have used this demographic because there are plenty of contemporary examples of incentives being used in the context of sterilisation. Our sources included empirical studies, journals in various disciplines, books, theses, documentary films, government publications, publications by nongovernmental organisations, articles in the lay press and information from reliable internet sources. We have highlighted a range of arguments, including those for and against incentivised sterilisation programmes. However, we openly declare our preference for rights based ethical frameworks over teleological ones.

\section{A Brief Overview}

The total number of sterilisations in India is running at 3.36 million per year [3]. The prevalence of female sterilisation of married women in India in 2015 was 36\%; the equivalent figure for men who have had a vasectomy was $0.3 \%$ [4]. Vasectomies, as a proportion of total sterilisations in India, have decreased from $20 \%$ in $2009 / 10$ [5] to $1.4 \%$ in 2018/19 [3]. Table 1 provides additional data about contraceptive use in India based upon the Ministry of Health and Family Welfare Annual Report for 2018-19:

[INSERT Table 1]

In 2013/14, India spent $85 \%$ of its fertility control budget on sterilisation [6]. Of the INR3.97 billion (US\$58 million) spent on female sterilisation, INR3.24 billion was spent on incentives and compensation [7]. In 2016, the Supreme Court of India in the case of Devika Biswas v Union of India ordered that sterilisation camps $[8,9,10]$ should cease within three years, a 
counsellor should see the potential acceptor as well as a doctor, and sterilisation targets should not result in coercion [11]. However, the incentivisation of sterilisation was not expressly prohibited at the time. The proposed constitutional amendment [1] endorses the promotion of national/ regional incentives with a view to limiting family size. Here the incentivisation is being linked directly to broader decisions around family planning, rather than to specific medical procedures/ narrow contraceptive options [12]. The merits of the former are for another paper - our focus is on direct incentivisation of sterilisation as a form of contraception. We will argue that the permanency and life changing nature of sterilisation is an important consideration for these policy measures [13].

\section{Demographic and Cultural Issues}

It is freely acknowledged that commenting on this subject in a meaningful way is fraught with difficulty due to cultural complexity. Citizens belonging to higher social classes tend to choose and undergo sterilisation in private hospitals in a high-quality clinical environment. Poorer people may opt for sterilisation as an expression of pragmatic agency in the context of their precarious economic circumstances, unequal gender relations and constantly weakening bodies [14]. Intersectionality [15] has featured prominently in sterilisation, with acceptors coming disproportionately from vulnerable groups - including those from lower educational and socio-economic groups [16]. These intersectional features can create an environment that makes it more likely that incentives, and other default State practices or policies, will have a coercive or adverse impact on individual autonomy, which may never be fully realisable in any event [17]. Our general concern is centred on the way intersectionality impacts on the exercise of State power and consequential justice, although the identity of individuals might be impacted too [18]. 


\section{Policy Measures}

A range of policy measures or instruments are available to State actors (and officials who represent them) to control fertility - from compulsory medical examination checks and forced sterilisation, to subtler forms of control including education, reward, incentive and penalty measures. These policies can be divided into those that mandate individual action or consequences (negative), and those that aim to influence or otherwise facilitate specific decisions and outcomes (positive). States can use 'negative' policy instruments to influence birth rates, including punishments, penalties or other sanction on those who refuse sterilisation or any other attempt to control their fertility. For example, in India ration cards have been withheld from eligible couples who refuse sterilisation [19]. Further, parents who fail to produce sterilisation certificates have been refused nutritional supplements for their existing children. From 2001 in Maharashtra, a third child was not entitled to food and other subsidised goods offered under the public distribution scheme [20].

Positive policy measures can be subdivided into nudges, boosts and other incentive measures either intended to benefit the individual patient or designed to achieve wider community goals. Although, our focus is on positive deliberative measures, both types of policy can be combined to achieve their intended effects - as evidenced during the Gandhi emergency period in the 1970s [21]. Nudges 'seek to affect decision-making by semi-conscious or unconscious "altering defaults" in the framing of choices' [22, 23] and can be aimed at correcting detrimental behaviours impacting on the individual or others [24]. A nudge can be categorised as an intervention or practice that prioritises a default outcome - requiring an 
individual to make an active choice to avoid that pre-set outcome. Nudges are in operation in schemes that require an active 'opt out' to avoid the default consequence.

Conversely, boosts are designed to "extend people's decision-making competence rather than co-opting their deficits" [24]. Boosts 'can target the individual's skills and knowledge, the available set of decision tools, or the environment in which decisions are made' [25]. The concept of 'boosts' has become increasingly popular, partly because of the emphasis on enhancing existing competency, and because nudges have attracted criticism for their tendency to treat individuals as "mindless, passive decision makers" [25].

Incentives are normally addressed explicitly and directly at an individual or a specific group (less common with nudges) and are designed to change or influence the behaviour or decision-making of that individual/ group [12]. Relevant examples include an offer to cover lost wages or pay direct food/ transport costs associated with a sterilisation, or an offer of payment to a third party for recruitment of sterilisation acceptors. In this paper, we are not concerned with strategies that use the 'common good' as the exclusive benefit on offer to the acceptor [12].

\section{The Ethical Arguments}

State-supported incentives are capable of influencing the wider public narrative, and can create subtle forms of pressure and influence on decision-makers, particularly when coupled with the wider promotion of responsible reproduction within a community [21]. If a State promotes 'responsible reproduction' and associates that with sterilisation, it can set up subtle pressure mechanisms that have the capacity to label 'non-acceptors' as irresponsible 
community members. This is significant if the target of the incentive (acceptor, motivator or provider) is a member of a group(s) with pre-existing vulnerability. Incentive offers to groups within a community that rely on acceptance by a large proportion of that group, can create subtle forms of pressure as well as a platform for coercion [12]. The need for openness and honesty about the objectives of and process for development of any incentive policy measure are, we believe, self-evident [12].

When evaluating incentives, we should differentiate the type of benefit, reward or financial compensation that is available to the target agent (i.e. the individual or group to whom the incentive is directed). We should also distinguish between benefits directed towards particular subjects or individuals, and recognise that incentives directed at multiple agents can combine to collectively influence overall behaviour and outcomes. In India, this has involved the use of State incentives directed at individual families, patients, healthcare providers and third-party motivators [21]. Some incentives may only reimburse an individual for out-of-pocket expenses, facilitating the attendance of the acceptor at the treating clinic. Others may include an element of extra reward for the acceptor or for members of their family. The personal circumstances of the potential acceptor and their family may affect the persuasive impact of the reward - a vulnerable individual with limited economic means may be more prone to impact by offers of this type [26]. The promise of an incentive when coupled with the threat of sanction may be particularly effective in 'persuading' vulnerable individuals.

Cash payments were common in India for sterilisation acceptors from the 1960s onwards, but inducements for female sterilisation have included goods such as televisions and pressure cookers too. Women acceptors are typically paid INR1,000 to INR1,400 (equivalent to 
almost a month's income in rural areas) [27]. A recent Annual Report confirms that vasectomy acceptors using public facilities will receive INR2,000 in 'high-focus' states and INR1,100 elsewhere; female sterilisation acceptors using public facilities will receive INR1,400 in high-focus states and INR600 elsewhere [28]. In some cases, the incentive cash sums have been more than twice as much in value as average monthly wages [29], large sums having the capacity to make a disproportionate impact on vulnerable groups.

The use of performance-based incentives for community family planning programmes is fairly widespread across the world, with sales commissions for uptake and referral payments for women using long-acting or permanent contraceptive methods dominating [30]. A scheme for six high-focus states in India (the Santushti Strategy) incentivised private health providers when they performed 10 or more sterilisations per month. This type of scheme has the capacity to undermine the 'free and informed' nature of the consent process because healthcare professionals (HCP) have to address the implicit influence of additional personal benefit. These schemes set up potential conflict and tension between the personal interests of the HCP and their beneficent duties to their patient.

Mass sterilisation campaigns have also used lay workers/ 'motivators' to recruit 'acceptors' in India. Some Indian States took extreme measures with the use of motivators and the use of recruitment targets: in Madhya Pradesh a Tata Nano car was offered to motivators for recruiting 500 subjects for an operation, a fridge for 50 and a gold coin for 25 [31]. Motivators are typically paid INR150 for each individual brought to be sterilised [32, 33]. In June 2012, Human Rights Watch interviewed more than 50 health workers in two districts in Gujarat and all of them had been assigned individual targets for female sterilisation [34]. 
Where a third-party agent is incentivised, this may add to social and other pressure on individuals who might already be weighing up the benefits for themselves and their wider family. In some cases, the healthcare provider or agent will be eroding or receiving a cut of the incentive that would otherwise have been available to the acceptor [21]. Sales commission for motivators can also distort what family planning options are offered to women - for example, the promotion of short-term over long-term contraceptive methods, if commission is only available following immediate take-up [30]. Further, we should not ignore the circumstances of the motivator/ provider - they may be vulnerable to the effects of the incentive and commission-based financial remuneration may be unfair to those from lower socio-economic backgrounds [30].

The International Federation of Gynecology and Obstetrics (FIGO) condemns inducements, pressure and coercion in relation to sterilisation, claiming that coercion brings a reproductive health programme into disrepute, jeopardising the limitation of fertility [35]. Individual freedom and reproductive autonomy are clearly important human values, especially for women who bear the physical burden of pregnancy. International law says that couples should have the right to decide freely and responsibly on the number, spacing and timing of their children [36], although whether this provides an unqualified right to bear any number of children is arguable [12]. Reproductive liberty demands that sterilisation decisions should be free of undue influence by third parties. State endorsed or facilitated incentives, penalties and other forms of coercion have the potential to erode and negatively impact on this conception of reproductive liberty and autonomy. However, we must also recognise that these influences and decisions are occurring in circumstances where autonomy may already be compromised or qualified $[12,17]$. We agree with Bellows et al. that the challenge is to 'construct 
incentives that are effective but not coercive, where one does not merely shift the coercive power to community leaders' [30].

We also need to be cautious about our ethical evaluation of incentive measures and not 'make broad brush assumptions about "behaviour change" interventions as if they were homogeneous in type, design, intended effect, mechanism of action, or underlying ethical norms' [22]. Further, our response will be influenced by the specific ethical lens we decide to employ and whether emphasis is placed on individual rights, community justice or collective goals [22]. Those in favour of incentives, tend to place greater emphasis on the collective management of population levels, or the achievement of wider population health benefits [30]. Whilst, there has been a shift towards the recognition of individual reproductive rights [7, 37], incentives are still widely used in family planning programmes across the world [30]. Even if consequentialist [38] sterilisation policies can be justified, State actors still need to establish (1) that these are effective means to achieve the intended goal(s) and (2) that due regard has been given to the broader concepts of justice and equality [12] for those targeted by any collective incentive scheme. Given that there is incomplete evidence about the effectiveness of different types of incentive [30], the use of collective measures in relation to sterilisation makes this evaluation especially problematic.

The availability of other effective and publicly acceptable contraceptive options may also be relevant. Past negative experience with intrauterine devices may have influenced the development of sterilisation policies in India [21]. The public narrative around options and the balanced availability of incentives for reversible and irreversible forms of contraception are also likely to be important. Again, we need to be careful that incentive schemes do not 
themselves accidentally alter what contraceptive options are prioritised, irrespective of individual interests [30].

The timing of incentives may also be important, both in terms of when the promise is made and when the benefit is received [12]. Benefits offered at a time of vulnerability for an individual (e.g. at, or shortly after, birth) are problematic if the decision-making and information-receiving processes are potentially impaired [13] (see Table 1). FIGO specifically rules that the consent process must not be timed when women are in pain [35].

Belief that incentives will be fulfilled is likely to be important in communities that have experienced historical broken promises in relation to incentives [21]. Where a promised reward or benefit is deliberately withheld it undermines the informational component of consent. It is therefore important that there are transparent mechanisms available to record and adjudicate individual incentive regimes and payments.

Rewards that do not directly benefit the acceptor should be approached with caution, and should point against the use of motivator or provider rewards based on numeric procedural outcomes if they create a tension between the interests of the motivator and any duty of care owed to the acceptor [7]. Payments to acceptors that exceed direct out-of-pocket expenses are more likely to undermine autonomous decision-making, especially if directed to those of low socio-economic status [7]. Sterilisation incentives should only be considered in communities that offer a range of accessible contraceptive options; and safe sterilisation methods should be available to all genders with proper non-directive counselling mechanisms. It is equally important that the use of reversible forms of contraception must not be coercive or directed at the target groups highlighted above [15, 21, 39]. Finally, whilst 
local operation of incentive schemes may offer political distance, it ought not to extricate central policymakers from responsibility for coercive practices that they have actively, albeit indirectly, facilitated [30].

\section{Conclusions}

With the development and introduction of highly effective reversible methods of contraception, there are alternatives to sterilisation. Coercive sterilisation programmes are not appropriate, although abuse still occurs around the world. Sterilisation is an option that should be readily available as part of an overall reproductive health service for those who request it. It is important that potential acceptors have access to adequate informational tools and education provision to be able to make informed decisions about their reproductive options.

In this paper, we have argued for specific caution around the future use and implementation of incentive schemes in relation to sterilisation. We do not claim that incentive schemes have no value in health care generally or reproductive health care more specifically. Rather our intention is to highlight the specific issues and wider concerns where the outcome is likely to be permanent and life changing for the acceptor. We are especially troubled by incentives directed to service providers or third-party motivators, or those which involve more than basic reimbursement for expenses/ losses directly incurred in connection with the procedure. 


\section{Source of Funding}

None.

\section{Disclosure statement}

The authors report no conflict of interest. 


\section{References}

1. The Constitution (Amendment) Bill, 2020 (Insertion of new article 47A), Rajya Sabha(2020).

2. SCC. The SCC Online Blog [Internet]: EBC Publishing. 2020. Available from: https://www.scconline.com/blog/post/2020/02/11/the-constitution-amendment-bill2020-introduced-in-rajya-sabha-bill-to-encourage-two-child-policy/

3. MOHFW. Annual Report 2018-19. New Delhi: Ministry of Health \& Family Welfare; 2020.

4. UN. World contraceptive use New York: United Nations, Department of Economic \& Social Affairs; 2019. Available from:

https://www.un.org/en/development/desa/population/publications/dataset/contraceptio n/wcu2019.asp

5. SyamRoy B. India's journey towards sustainable population. Cham: Springer; 2017.

6. Dhar A. Gendered approach to sterilisation. The Hindu. 20151 January. Available from: https://www.thehindu.com/sci-tech/health/policy-and-issues/genderedapproach-to-sterilisation/article6742284.ece

7. Muttreja P, Banerjee A, Apte K, et al. Robbed of choice and dignity: Indian women dead after mass sterilisation. New Delhi: Population Foundation of India; 2014.

8. Krishnakumar S. Pioneering experiment in massive vasectomy camps. Stud Fam Plann. 1972;3:177-185.

9. Padmadas SS. Inside India's sterilisation camps: The Conversation; 2014. Available from: http://theconversation.com/inside-indias-sterilisation-camps-34208

10. Masih M, Barpanda S, Wynne Z. Mistreatment and coercion: unethical sterilization in India. New Delhi: Socio-Legal Information Center; 2018. 
11. Ashok KM. Are you framing national health policy or not: SC asks Centre: Live Law.in; 2016 [cited 201829 January]. Available from: www.livelaw.in/framing$\underline{\text { national-health-policy-not-sc-asks-centre/ }}$

12. Veatch RM. Government population incentives: ethical issues at stake. Studies in Fam Plan. 1977;8:100-108.

13. Rowlands S, Wale J. Sterilisations at delivery or after childbirth: addressing continuing abuses in the consent process. Global Public Health. 2019;14(8):11531166. doi: 10.1080/17441692.2019.1583265.

14. Luksaite E. The intimate state: female sterilisation, reproductive agency and operable bodies in rural North India: Brunel University, London; 2016.

15. Sifris R. The involuntary sterilisation of marginalised women: power, discrimination and intersectionality. Griffith Law Review. 2016;25:45-70.

16. Thakor VH, Patel VM. The Gujarat massive vasectomy campaign. Stud Fam Plann. 1972;3:186-192.

17. Manson NC, O’Neill O. Rethinking informed consent in bioethics. Cambridge: Cambridge University Press; 2007.

18. Cooper B. Intersectionality. In: Disch L, Hawkesworth M, editors. The Oxford Handbook of Feminist Theory. Oxford: Oxford University Press; 2016.

19. Minkler M. "Thinking the unthinkable": the prospect of compulsory sterilization in India. Int J Health Services. 1977;7:237-248.

20. Chayanika. Maharashtra state population policy. Indian Journal of Medical Ethics. 2001;IX:22-23.

21. Solinger T, Nakachi M. Reproductive states: global perspectives on the invention and implementation of population policy. New York: Oxford University Press; 2016. 
22. Ashcroft R. Incentives, nudges and the burden of proof in ethical argument. J Med Ethics. 2017;43:137.

23. Sunstein CR. Choosing not to choose: understanding the value of choice. Oxford University Press; 2015.

24. Hertwig R. Beyond nudging: how to boost medical decision making. Keynote. 16th Biennial European Conference of the Society for Medical Decision Making; 13 December; London2016.

25. Grüne-Yanoff T, Hertwig R. Nudge versus boost: how coherent are policy and theory? Minds \& Machines. 2016;26:149-183.

26. Cleland J, Mauldin WP. The promotion of family planning by financial payments: the case of Bangladesh. Studies in Fam Plan. 1991;22:1-18.

27. Doane D. Is India's sterilisation programme barbaric and anti-women? Guardian. 201412 November. Available from: https://www.theguardian.com/globaldevelopment-professionals-network/2014/nov/12/indias-sterilisation-drive-is$\underline{\text { barbaric-and-disproportionately-targeted-at-women }}$

28. MOHFW. Annual Report 2017-18. New Delhi: Department of Health \& Family Welfare; 2019.

29. Vicziany M. Coercion in a Soft State: The family planning program of India: Part 2: The sources of coercion. Pacific Affairs. 1982;55:557-592.

30. Bellows NM, Askey I, Bellows B. Review of performance-based incentives in community-based family planning programmes. J Fam Plann Reprod Health Care. 2015;41:146-151.

31. Mishral M. Bring 500 for sterilization, take home a Nano Gurgaon2013 [cited 20188 February]. Available from: https://timesofindia.indiatimes.com/city/bhopal/Bring$\underline{\text { 500-for-sterilization-take-home-a-Nano/articleshow/19013834.cms }}$ 
32. Bader S. Is incentive-based pay for India's commmunity health workers working? : Devex; 2017. Available from: https://www.devex.com/news/is-incentive-based-payfor-india-s-community-health-workers-working-90502

33. Brault MA, Schensul SL, Singh R, et al. Multilevel perspectives on female sterilization in low-income communities in Mumbai, India. Qualitative Health Research. 2016;26:1550-1560.

34. HRW. India: target-driven sterilisation harming women: Human Rights Watch; 2012 [cited 20182 July]. Available from: https://www.hrw.org/news/2012/07/12/india$\underline{\text { target-driven-sterilization-harming-women }}$

35. FIGO. Ethical issues in obstetrics and gynecology London: International Federation of Gynecology and Obstetrics; 2015. Available from: http://www.figo.org/sites/default/files/uploads/wgpublications/ethics/FIGO\%20Ethical\%20Issues\%202015.pdf4893.pdf

36. UN. Convention on the Elimination of all forms of Discrimination Against Women. New York: United Nations; 1979.

37. UN. Report of the International Conference on Population and Development (Cairo, 5-13 September 1994). New York: United Nations; 1994.

38. Beauchamp TL, Childress JF. Principles of biomedical ethics. 7th ed. New York: Oxford University Press; 2013.

39. Rowlands S, Ingham R. Long-acting reversible contraception: conflicting perspectives of advocates and potential users. BJOG. 2017;124:1474-1476. doi: https://doi.org/10.1111/1471-0528.14699 